\title{
TRES DESAFÍOS PARA LA INVESTIGACIÓN EN LAS ÁREAS DE GESTIÓN EN AMÉRICA LATINA
}

\author{
DOI: www.doi.org/10.54198/innova08.01
}

\section{Fernando de Almeida Santos ${ }^{1}$}

Las revistas científicas han jugado un papel importante en el registro histórico y la difusión de la investigación en América Latina. Este hecho consiste en un movimiento mundial que requiere un importante crecimiento en la cantidad y calidad de las revistas científicas.

Latindex (2021), que consiste en una red de instituciones que trabajan de manera coordinada para recopilar y difundir publicaciones científicas seriadas producidas en Iberoamérica, cuenta actualmente con 29.794 revistas en línea.

EDITORIAL

En ese sentido, es evidente que este crecimiento demuestra inversión y preocupación por la investigación científica, por lo que tenemos que continuar con las acciones para garantizar la innovación y el impacto social.

La investigación como principio científico y educativo forma parte de todo el proceso emancipatorio, en el que se construye el sujeto histórico autosuficiente, crítico y autocrítico, participante y capaz de reaccionar contra la situación del objeto y no cultivar al otro como objeto. La investigación como diálogo es un proceso cotidiano que es parte integral del ritmo de vida, producto y motivo de los intereses sociales en la confrontación, la base del aprendizaje que no restringe la mera reproducción; En el sentido más simple, puede significar saber, conocer, informarse para sobrevivir, enfrentar la vida conscientemente. (Demo, 2006. P.42-to 43).

\footnotetext{
${ }^{1}$ Doctor en Ciencias Sociales con Postdoctorado en Ciencias Contables, en la Pontificia Universidad de São Paulo (PUC-SP), Master en Administración General, Licenciado en Administración de Empresas, en Ciencias Contables y en Administración del Gobierno, Miembro del Colegio de Contadores de Sao Paulo - CRC-SP (2108-2021), Actualmente es Coordinador del Máster en Ciencias Contables en la PUC-SP Investigador en NUPE - Centro Universitario ENIAC. Brasil https://orcid.org/0000-0002-1716$\underline{2802}$
} 
Con una población de casi 1 billón de personas, distribuidas en 35 países, América Latina necesita fomentar la investigación aplicada, especialmente en las áreas de Gestión.

Cabe destacar que las áreas relacionadas con la gestión son fundamentales para el desarrollo de los países y para asegurar la competitividad de las instituciones. Administración, Ciencias Contables, Marketing, Administración Financiera y áreas afines, son Ciencias Sociales que solo tienen sentido a través de la aplicación, por lo que de la misma manera la investigación necesita ser aplicada.

Los países de América Latina necesitan de estas ciencias, cuya mayor prueba son las dificultades burocráticas que requieren soluciones para que la sociedad crezca.

Para demostrar la necesidad de soluciones, presentamos la tabla 1, que contiene las posiciones de los países sudamericanos, según la dificultad para hacer negocios, presentada en el ranking mundial de Doing Business 2020.

\begin{tabular}{|c|c|c|}
\hline Rank & Economy & DB score \\
\hline 59 & Chile & 72.6 \\
\hline 67 & Colombia & 70.1 \\
\hline 76 & Peru & 68.7 \\
\hline 101 & Uruguay & 61.5 \\
\hline 124 & Brazil & 59.1 \\
\hline 125 & Paraguay & 59.1 \\
\hline 126 & Argentina & 59.0 \\
\hline 129 & Ecuador & 57.7 \\
\hline 134 & Guyana & 55.5 \\
\hline 150 & Bolivia & 51.7 \\
\hline 188 & Venezuela, RB & 30.2 \\
\hline
\end{tabular}

Fuente: Doing Business 2020 (worldbank.org).

Concretamente, en Brasil, el área tributária es muy burocrática, ya que existen miles de leyes y regulaciones, con más de 90 impuestos complejos y diferentes interpretaciones, lo que dificulta el desarrollo de las empresas y permite miles de procesos legales anualmente. 
Tenemos el desafío de implementar y actualizar las Normas Internacionales de Contabilidad. Los procesos se han iniciado durante años, a través de la legislación local, las normas transnacionales y las propuestas globales, pero la implementación completa requiere conocimiento, investigación y revisión de la legislación nacional y los procesos comerciales internos.

La tecnología tiene que estar presente en el día a día de todos y la información es parte de las empresas, el estado y la vida de las personas. Las áreas orientadas a la gestión deben desempeñar este papel de contribuir a las transformaciones sociales. Las revistas científicas suelen desempeñar este importante papel, ya que muestran cómo se puede aplicar la ciencia.

Así que es hora de avanzar y preocuparse por cómo es posible contribuir aún más a la sociedad. Para continuar con esta mejora continua de la investigación, tenemos algunos desafíos, destacando:

a) Desarrollar y estandarizar formas de medir los impactos sociales: El número de publicaciones y el número de citas son banderas de impacto, pero ¿Cuál es el número de personas beneficiadas? ¿Cuál es la posibilidad de integrar investigaciones internacionales? ¿Cuál es la contribución al desarrollo humano? ¿Cuál es la forma y el contenido de la innovación? ¿Qué investigación se centra en los servicios que hoy en día es el sector más importante de la sociedad?

b) Asegurar la internacionalización, a través de redes de investigación y publicaciones en otros idiomas: La internacionalización es una realidad de varios países y centros de investigación, tenemos que seguir siendo competitivos en un entorno donde hay disputas en los mercados globales y de alta tecnología.

c) Mejorar, internacionalizar y ampliar el impacto de las instituciones educativas: Las instituciones educativas deben estar más cerca de la sociedad, especialmente de las empresas públicas, privadas y del tercer sector, con proyectos de investigación, enseñanza y extensión cada vez más aplicados y efectivos.

Creo que estos son los 3 principales desafíos para las áreas de gestión en América Latina. 


\section{Referencias}

Demo, Pedro. (2006). Pesquisa: principio científico e educativo. 12. Ed. São Paulo: Cortez, 2006.

Latindex (2021). Descripción.

https://www.latindex.org/latindex/descripcion

The World Bank. (2021) Doing Business 2020.

https://www.worldbank.org/en/home 